\title{
Location and distribution of micro-inclusions in the EDML and NEEM ice cores using optical microscopy and in situ Raman spectroscopy
}

\author{
Jan Eichler ${ }^{1,2}$, Ina Kleitz ${ }^{1}$, Maddalena Bayer-Giraldi ${ }^{1}$, Daniela Jansen ${ }^{1}$, Sepp Kipfstuhl ${ }^{1}$, Wataru Shigeyama ${ }^{3,4}$, \\ Christian Weikusat ${ }^{1}$, and Ilka Weikusat ${ }^{1,2}$ \\ ${ }^{1}$ Alfred Wegener Institute Helmholtz Centre for Polar and Marine Research, 27568 Bremerhaven, Germany \\ ${ }^{2}$ Department of Geosciences, Eberhard Karls University Tübingen, 72074 Tübingen, Germany \\ ${ }^{3}$ Department of Polar Science, SOKENDAI (The Graduate University for Advanced Studies), 10-3 Midori-cho, Tachikawa, \\ Tokyo, 190-8518, Japan \\ ${ }^{4}$ National Institute of Polar Research, 10-3 Midori-cho, Tachikawa, Tokyo, 190-8518, Japan
}

Correspondence to: Jan Eichler (jan.eichler@awi.de)

Received: 22 October 2016 - Discussion started: 30 November 2016

Revised: 21 March 2017 - Accepted: 24 March 2017 - Published: 5 May 2017

\begin{abstract}
Impurities control a variety of physical properties of polar ice. Their impact can be observed at all scales from the microstructure (e.g., grain size and orientation) to the ice sheet flow behavior (e.g., borehole tilting and closure). Most impurities in ice form micrometer-sized inclusions. It has been suggested that these $\mu$ inclusions control the grain size of polycrystalline ice by pinning of grain boundaries (Zener pinning), which should be reflected in their distribution with respect to the grain boundary network. We used an optical microscope to generate high-resolution large-scale maps $\left(3 \mu \mathrm{m}\right.$ pix $\left.^{-1}, 8 \times 2 \mathrm{~cm}^{2}\right)$ of the distribution of micro-inclusions in four polar ice samples: two from Antarctica (EDML, MIS 5.5) and two from Greenland (NEEM, Holocene). The in situ positions of more than $5000 \mu$ inclusions have been determined. A Raman microscope was used to confirm the extrinsic nature of a sample proportion of the mapped inclusions. A superposition of the 2-D grain boundary network and $\mu$-inclusion distributions shows no significant correlations between grain boundaries and $\mu$ inclusions. In particular, no signs of grain boundaries harvesting $\mu$ inclusions could be found and no evidence of $\mu$ inclusions inhibiting grain boundary migration by slow-mode pinning could be detected. Consequences for our understanding of the impurity effect on ice microstructure and rheology are discussed.
\end{abstract}

\section{Introduction}

Polar meteoric ice is one of the purest materials on Earth. Impurity mass concentrations in the Antarctic ice sheet vary between ppbm during warm periods and ppmm in the most dusty layers in cold periods (Legrand and Mayewski, 1997; Faria et al., 2010). Values for the Greenland ice sheet are approximately 10 times higher. Impurities enter the ice sheet during deposition in the form of terrestrial dust, salt particles and other aerosols, e.g., from bio-activity, ocean, volcanoes or combustion, or in the form of gas inclusions from air bubbles. Trace substances are a subject of intense ice core studies for many reasons. Their chemical and isotopic compositions can be linked to atmospheric and climatic processes (climate proxies), and their analysis provides an important insight into processes and constraints of the past of Earth's climate (Dansgaard et al., 1982; GRIP Project Members, 1993; EPICA community members, 2004, 2006; Kuramoto et al., 2011; Wegner et al., 2015). When linked to geologic events (Sigl et al., 2015), they can serve as absolute chronological markers for ice core dating (sulfate and tephra layers from volcanic eruptions; Gow and Meese, 2007). And finally, many material properties of ice are controlled or modulated by its impurity content. This is the case for the dielectric constant and electrical conductivity, measured systematically using dielectric profiling (DEP) and electrical conductivity method (ECM) (Wolff et al., 1997; Stillman et al., 
2013; Taylor et al., 1993; Wilhelms et al., 1998), but it also applies to mechanical properties of ice - such as creep behavior and viscosity - which are of great interest with respect to ice rheology and ice sheet dynamics. The influence of various impurities on deformation rate has been observed in laboratory tests (e.g., Dahl-Jensen et al., 1997) as well as in the field from borehole tilting and closure (e.g., Fisher and Koerner, 1986). The link between impurity content and strain rate becomes most evident when comparing ice-age ice with ice from warm periods. Observations show that the impurityrich ice-age ice deforms on average 2.5 times faster in simple shear (Paterson, 1991). Several explanations for this effect have been proposed, but the responsible mechanisms still remain under discussion. Since ice-age ice usually develops a different microstructure - e.g., stronger crystal preferred orientation (CPO) or smaller grains (Paterson, 1991; Cuffey et al., 2000) - the higher strain rates may result from an interplay between impurities, microstructure and recrystallization.

With increasing interest in the impurity content, analysis methods have been refined over the past years. Continuous flow analysis (CFA) became a standard part of ice core processing (Kaufmann et al., 2008) due to its effectivity and high depth resolution. However, the aim to understand impurityrelated processes in polycrystalline ice requires the application of approaches dedicated to the solid state. Thus, advanced analytical techniques, such as scanning electron microscopy (SEM), Raman spectroscopy or laser ablation inductively coupled plasma mass spectrometry (LA-ICPMS), became popular with glaciologists. However, each of these methods brings its own specifications and constraints and the results often lead to contradictory conclusions. Comparative studies may be necessary to clear these discrepancies in future.

The composition, form, location and distribution of impurities are different in ice compared to liquid water. Due to the electric dipole moment of the $\mathrm{H}_{2} \mathrm{O}$ molecule, water is a good solvent. In contrast, the ice crystal is not and will reject most extrinsic substances out of the matrix, forming a second phase (Petrenko and Whitworth, 1999). Only a few elements are theoretically able to be incorporated into the ice lattice. According to Jones (1967) and Jones and Glen (1969), $\mathrm{F}^{-}, \mathrm{Cl}^{-}, \mathrm{K}^{+}$and $\mathrm{NH}_{4}^{+}$in low concentrations are able to substitute oxygen atoms or enter the ice lattice interstitials. In both cases they would introduce ionic and Bjerrum defects and significantly affect the charge carrier density of the ice crystal. Since protonic defects can alter dislocation mobilities, ice doped with these species manifests higher strain rates than pure ice (Glen, 1968). However, the doping experiments by Jones and Glen probably represent upper bounds with respect to natural ice, which is formed from snow flakes inheriting impurities from atmospheric processes. Another widely discussed form of ice impurities was proposed by Wolff and Paren (1984), who interpreted DC conductivity as caused by conduction through acidic environments along grain boundaries and triple junctions. The authors suggested that acids like $\mathrm{HCl}, \mathrm{HNO}_{3}$ and $\mathrm{H}_{2} \mathrm{SO}_{4}$ would concentrate at grain boundaries lowering the eutectic point of the solute and thus forming liquid veins. The existence of an acidic vein network was supported by Mulvaney et al. (1988), who found sulfur at three triple junctions using energy-dispersive $\mathrm{X}$ ray spectroscopy (EDX), and Fukazawa et al. (1998), who measured a sulfate peak in a triple junction using a Raman microscope. However, other Raman-spectroscopic studies by Ohno et al. $(2005,2006)$ and Sakurai et al. (2011) found most (or all) sulfates forming salt particles. In contrast, EDX experiments by Cullen and Baker (2001), Barnes et al. (2002), Barnes (2003), Baker et al. (2003) and Iliescu and Baker (2008) found traces of sodium, chlorine and sulfur in filaments, which would grow out of grain boundaries after controlled surface sublimation of natural ice samples. Della Lunga et al. (2014) analyzed the distribution of a variety of elements in discrete samples from the glacial part of the NGRIP ice core using UV-LA-ICPMS. No correlation was found between impurities and grain boundaries in cloudy bands, but the authors observed concentration peaks at grain boundaries in the cleaner parts of the ice. There is no consensus yet about the abundance and relevance of impurity segregation to grain boundaries.

In terms of mass fraction, most impurities form second phase inclusions, i.e., inclusions of extrinsic material or another lattice-incoherent phase (Ashby, 1969; Alley et al., 1986a; Humphreys and Hatherly, 2004). Due to their typical size of a few micrometers we call them " $\mu$ inclusions" in the following. Water-insoluble dust particles as well as watersoluble particulate salts are the most abundant $\mu$ inclusions. Their concentrations are highly variable along the ice cores. For instance, dust concentrations in the EDML ice core measured by CFA (Wegner et al., 2015) vary between $10^{3}$ and $10^{5}$ particles per milliliter. Strata with high concentrations of $\mu$ inclusions are visible in ice cores and are often called "cloudy bands" (Svensson et al., 2005). $\mu$ inclusions appear under an optical microscope as dark spots near the optical detection limit - commonly referred to as "black dots" (see Fig. 1). When using optical microscopy it is impossible to examine their state of aggregate, shape, color or composition, and thus the term "black dot" reflects not only their visual appearance but also our uncertainty about their nature and composition.

High concentrations of $\mu$ inclusions are usually associated with certain changes in ice microstructure. On the large scale, ice-age ice was reported to be characterized by stronger CPO (e.g., Gow and Williamson, 1976; Paterson, 1991; Faria et al., 2014a) and cloudy ice exhibits in general smaller grain sizes than clean ice. Since grain growth involves grain boundary migration, impeding grain boundary movement by $\mu$ inclusions would consequently have a grain-size-reducing effect. The attractive force between $\mu$ inclusions and grain boundaries is known from material sciences and has been first modeled by Zener (in Smith, 1948) - Zener pinning. 


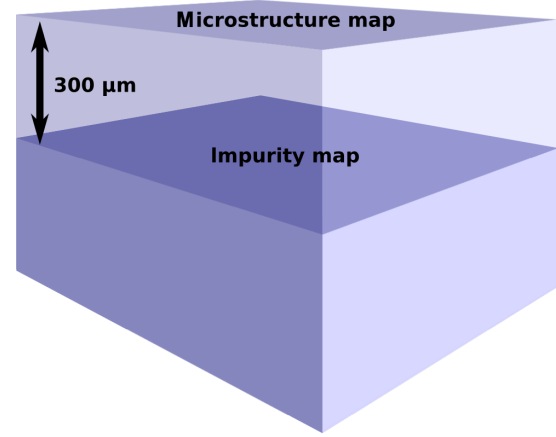

(a)
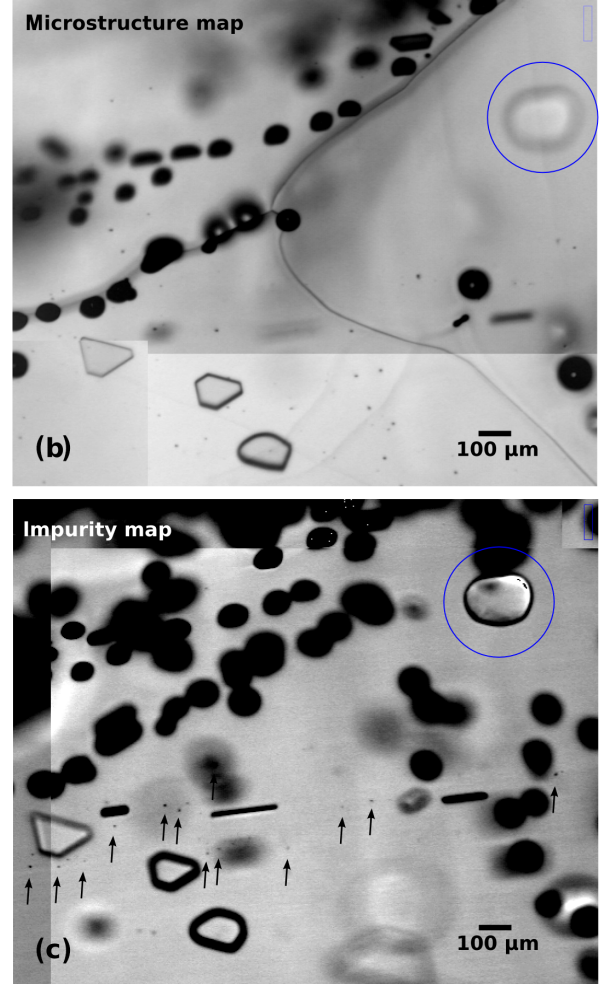

Figure 1. (a) Schematic of positioning stacked microstructure maps from surface and inside the sample. The focus distance between the two mapping planes in general depends on the application of this method (e.g., investigation of air inclusions or $\mu$ inclusions). In order to correlate $\mu$ inclusions and grain boundary grooves, for this study a distance of $300 \mu \mathrm{m}$ has been chosen. (b) Surface-focused photomicrograph from EDML-2371.9 (2371 m, drilled in 2006). The image shows three grain boundaries as black thin curves and a triple junction. "Black dots" in this map type are due to surface pollution by frost particles and should not be confused with $\mu$ inclusions in the impurity maps. Below the surface - and slightly out of focus - a clathrate hydrate (marked with blue circle) and three plate-like inclusions (hexagonal objects) are visible. Roundish black objects of the size of up to $100 \mu \mathrm{m}$ are secondary gas inclusions formed by relaxation of the material. At the surface they are clearly attached to the left grain boundary. (c) Photomicrograph focused ca. $300 \mu \mathrm{m}$ below the surface. The grain boundary grooves disappeared but objects in the sample volume came into focus - the clathrate hydrate and plate-like inclusions are sharp now. "Black dots" in this image (pinpointed with arrows) are chemical impurities in the form of $\mu$ inclusions.

When a migrating grain boundary passes a particle, its energy is reduced by the portion of the cross-sectional area. Depending on the grain boundary driving force, the pinning pressure and the mobility of the particles, grain boundary can be completely stopped (pinned), free itself after a while from the particles and continue its motion, or drag the particles with it. Alley et al. (1986a, b) reviewed the Zener theory and available data with respect to the pinning effect on normal grain growth (NGG) in cold ice. They differentiate between a low-velocity regime, where the grain boundary is pinned by the impurities, and a high-velocity regime, where the grain boundary continues its motion leaving the impurities behind. Alley et al. (1986b) conclude that pinning on $\mu$ inclusions occurs in high-velocity regimes and the concentration of microparticles is too low in general to significantly affect grain growth (the only exceptions are tephra layers from volcanic eruptions). Durand et al. (2006) simulated grain size evolution along the Dome Concordia ice core by modeling NGG controlled by pinning on dust particles. They suggest that dust particles will indeed impede grain growth if they concentrate at grain boundaries. However, a direct proof for such a particle distribution was not provided, since grain boundaries could not be imaged. In contrast, Raman measurements of $\mu$ inclusions in the Dome Fuji ice core, presented by Ohno et al. $(2005,2006)$, showed that major part of the particles (mostly sulfate salts) were located in grain interiors. Faria et al. (2010) evaluated relevant microstructure and impurity data concerning the integrity of the EDML ice core. According to their report, black dots in the microstructure mapping images do not accumulate along grain boundaries for depths down to $2300 \mathrm{~m}$. Only below this depth, and particularly in the deepest $200 \mathrm{~m}$ of the core, were accumulations at grain boundaries and on the surface of clathrate hydrates observed.

So far, studies on spatial distributions of $\mu$ inclusions in ice have been based on discrete observations of a few dust or salt particles. In order to discuss general concepts, such as the formation of the CFA signal, predominant form of impurities in situ and their effect on recrystallization (e.g., grain 
boundary pinning), more systematic and statistically relevant approaches are necessary. The aim of this study is to provide a more detailed insight into the in situ concentrations and distributions of $\mu$ inclusions. We mapped over $5000 \mu$ inclusions within four different ice samples from polar ice cores. Overall and local concentrations are estimated and compared with the available CFA data. Special attention is payed to the correlation between $\mu$ inclusions and the grain boundary network.

\section{Methods and sample material}

The state in which impurities are included in ice is different from their form in meltwater (CFA). In order to reveal their distribution and in situ form, more data based on direct measurements of ice samples are needed. Optical microscopy and Raman spectroscopy provide the opportunity to explore the interior of ice samples in a non-destructive way. This is a significant advantage over surface-based methods (e.g., SEM), where contamination and sublimation-related redistribution of impurities have to be considered (e.g., Barnes, 2003). We use microstructure mapping to create large area maps $\left(8 \times 2 \mathrm{~cm}^{2}\right)$ of the specimens surfaces and interiors. This microscopical technique was introduced by Kipfstuhl et al. (2006) and it enables us to pinpoint visible $\mu$ inclusions as well as grain and subgrain boundaries. We use a Raman microscope to prove that we are dealing with extrinsic material and to investigate the composition of selected $\mu$ inclusions.

As the lower impurity content in warm-period ice provide a better chance to observe and characterize the majority of $\mu$ inclusions over a large sample area and analyze their correlation with the microstructure, we focused our study on samples from warmer periods. Furthermore, one of the very few studies which found evidence for a connection of spatial distribution of impurities along grain boundaries reported this evidence as a characteristic of "clean" interstadial ice (Della Lunga et al., 2014). Four samples were analyzed: two from the EDML ice core (Antarctica) and two from the NEEM ice core (Greenland). The EDML samples (EDML-2371.4 and EDML-2371.9) originate from $2370 \mathrm{~m}$ depth which corresponds to the early Eemian (MIS5.5). The NEEM samples (NEEM-1346.2 and NEEM-1346.5) originate from the Holocene, $740 \mathrm{~m}$ below surface and around 4000 years b2k (Rasmussen et al., 2013).

\subsection{Impurity maps}

The sample preparation has been described by Kipfstuhl et al. (2006). Specimens of the thickness of around $1 \mathrm{~cm}$ are cut with a band saw (see cutting plan in Fig. 3d). Both surfaces are polished with a microtome knife and exposed to air for a few hours. Sublimation smoothens the surface and creates grooves at sites of high energy, where grain and subgrain boundaries intersect the surface. In this way 2-D maps of grain boundary networks and subgrain structures can be created (Binder et al., 2013). When focusing into the ice volume and choosing transmission light mode, surface features such as etching grooves fade out but other objects inside the sample come into focus. Typical features are gas inclusions (air bubbles and clathrate hydrates), relaxation features (secondary bubbles, plate-like inclusions) and $\mu$ inclusions (see examples in Figs. 1b, c and 2c, d). $\mu$ inclusions appear as dark spots near the resolution limit of the microscope.

We use an optical microscope (Leica DMLM) with a CCD camera (Hamamatsu C5405), frame grabber and a softwarecontrolled $x-y$ stage. Ice samples of up to $10 \mathrm{~cm}$ side length can be scanned at the resolution of $3 \mu \mathrm{mpix}^{-1}$. The final microstructure map is stitched from up to 1500 individually captured photomicrographs. We combine two of these scans for each sample - a microstructure map focused onto the surface to reveal grain boundaries and an impurity map focused ca. $300 \mu \mathrm{m}$ into the sample volume to visualize $\mu$ inclusions (see Fig. 1a). Such a stack of maps allows us to study inclusions in direct relation to the grain boundary network. Since $\mu$ inclusions are mapped within the sample volume, contamination is not an issue. Due to the obliquity and 3-D shape of grain boundaries, their positions inside the sample are not exactly the same as the etching grooves on the surface. To keep this uncertainty low the second scan must be focused close below the surface. Black dots in impurity maps were detected manually. The low contrast and size of black dots in the images did not support the application of automatic detection filters. Visual detection and manual counting of $\mu$ inclusions is a time-consuming process which requires a certain amount of patience and discipline. Since it is based on observer's subjective judgment, the results may contain an observer-dependent variance. The impurity maps presented in this study were generated by three observers independently, but using the same criteria. Partial comparison of the results at overlapping regions showed a good consistency within the data and thus confirmed the observer-dependent factor being minimal.

\subsection{Raman spectroscopy}

A confocal Raman microscope was used to analyze the composition and mineralogy of selected $\mu$ inclusions. The AWI cryo-Raman system consists of a WITec alpha $300 \mathrm{M}+$ with an UHTS 300 spectrometer and a Nd:YAG laser $(532 \mathrm{~nm})$ set up in the cryolab at $-15^{\circ} \mathrm{C}$ (Weikusat et al., 2015). Within the scope of this paper, the measured Raman spectra shall serve as a proof that the mapped black dots are in fact chemical impurities in the form of $\mu$ inclusions. A detailed analysis of the detected minerals is being prepared for publication. 

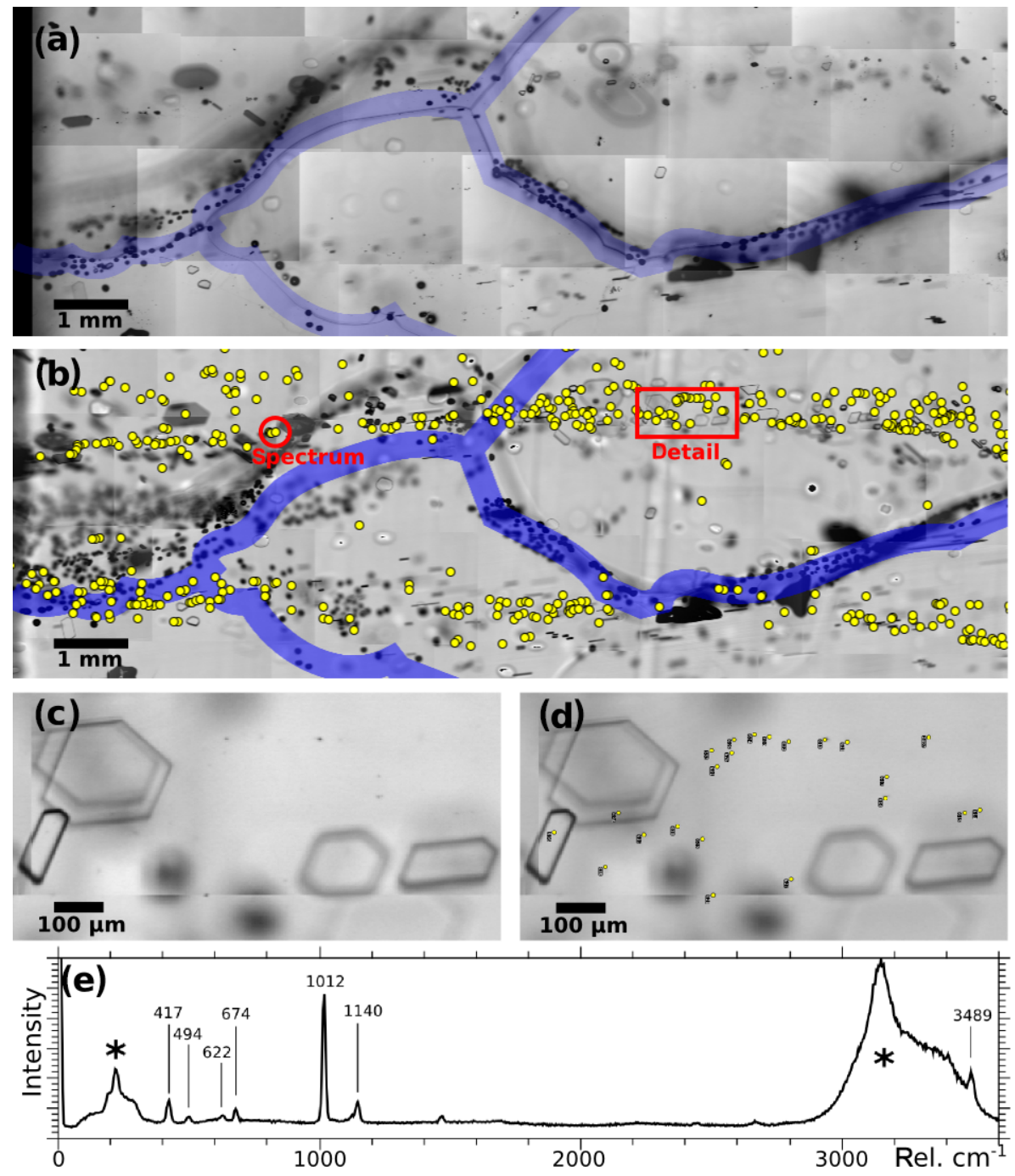

Figure 2. Double impurity layer in EDML-2371.9 (horizon 1 in Fig. 3). (a) Surface map with grain boundaries visible as thin dark lines highlighted with blue bands. Blurred lines are grain boundaries at the bottom side of the specimen which are out of camera focus. (b) Impurity map with marked $\mu$ inclusions (yellow circles) and grain boundary network from the surface map. Roundish black objects with the size of several tens of $\mu \mathrm{m}$ are secondary gas inclusions (micro-bubbles) formed due to relaxation (Weikusat et al., 2012). While $\mu$ inclusions follow horizontal layering, micro-bubbles trace the 3-D shape of the grain boundaries. (c) A high-resolution uninterpreted detail of the upper impurity layer is indicated by the red rectangle in (b). (d) Same detail with interpreted $\mu$ inclusions. (e) Example Raman spectrum of one $\mu$ inclusion from the upper layer (red circle). Parts of the signal marked with asterisk correspond to the ice spectrum. The positions of the proper peaks are quoted. The inclusion is a gypsum particle $\left(\mathrm{CaSO}_{4} \cdot 2 \mathrm{H}_{2} \mathrm{O}\right)$.

\section{Results}

Microstructure and impurity maps were generated for the four samples: EDML-2371.4, EDML-2371.9, NEEM-1346.2 and NEEM-1346.5. We localized $5784 \mu$ inclusions in total (in Figs. 2, 3, 5, 6 marked with yellow circles). Their size of 2-3 pixels in diameter would correspond to 6-9 $\mu \mathrm{m}$, but their appearance as "black dots" is probably produced by optical effect of much smaller particles of the typical dust size ca. 1-2 $\mu \mathrm{m}$ (Wegner et al., 2015). Raman measurements and correlation with CFA dust and $\mathrm{Ca}^{2+}$ peaks, however, confirm our assumption that these features are real $\mu$ inclusions.

\subsection{Raman spectroscopy}

A limited number of $\mu$ inclusions (20-40 per sample) were selected for the Raman analysis. Using a $50 \times$ lens and confocal mode, a great majority (around $90 \%$ ) of the $\mu$ inclusions could be found again in the Raman microscope. Additionally, their distance from the sample surface ( $z$ coordinate) could be measured due to the confocal setting. The $z$ coordinates of $\mu$ inclusions are Gaussian-distributed around the focal plane with a half maximum width of $200 \mu \mathrm{m}$. We accept this value as the depth of field of the mapping microscope and use it for the calculation of the volume fraction of the impurity maps. 

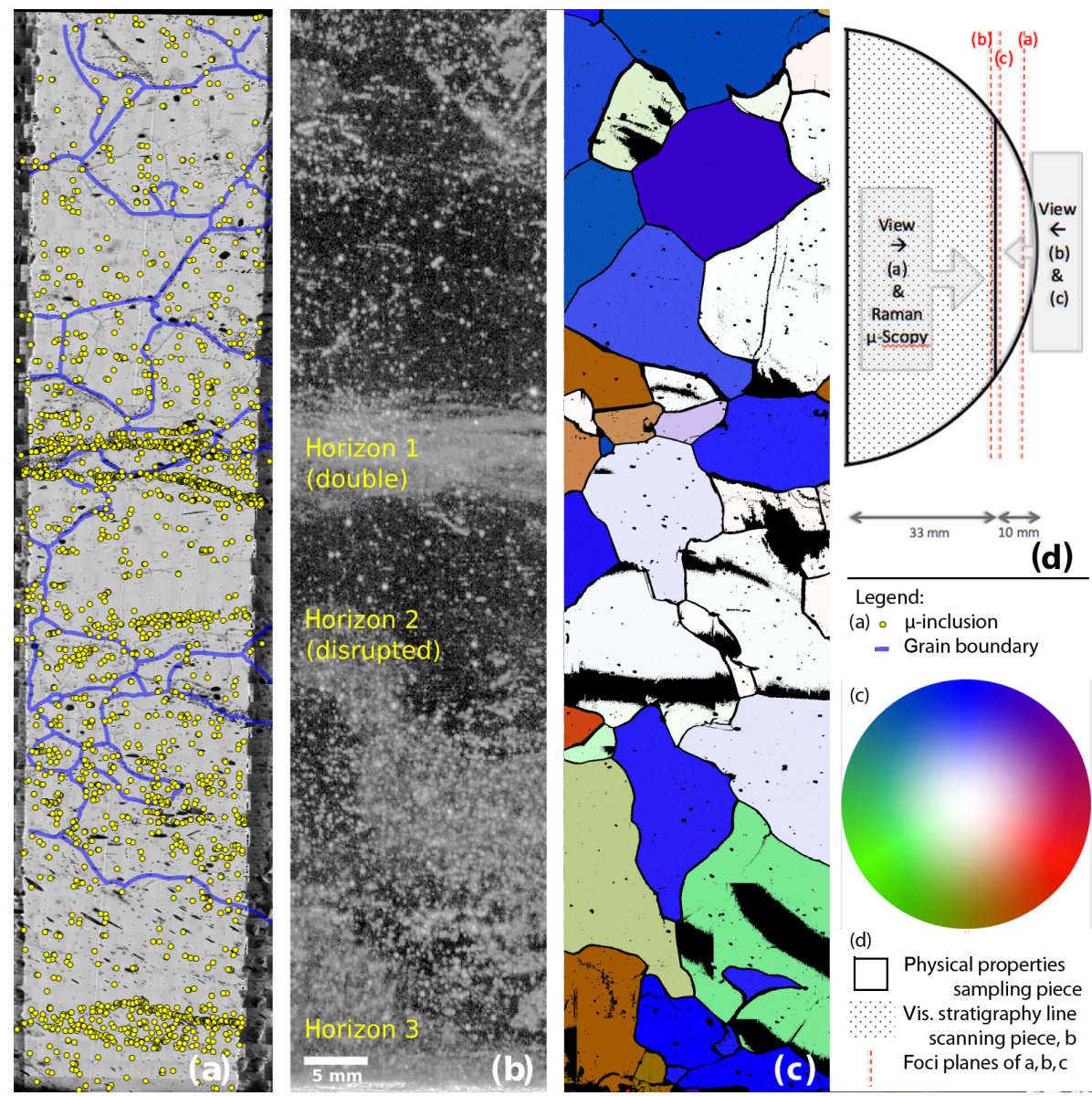

Figure 3. EDML-2371.9: (a) impurity map of the whole sample $(17 \mathrm{~mm} \times 76 \mathrm{~mm})$ with $2527 \mu$ inclusion (yellow circles) and grain boundaries from the surface map (blue bands). Blurred lines are grain boundaries at the bottom side of the specimen. Horizontal layers (1-3) of $\mu$ inclusion are clearly visible. (b) A detail from the line scanner image of the same part of the ice core. Horizon 1 is visible as a cloudy band. (c) $C$-axis orientations of individual grains projected into a horizontal plane. Vertical $c$ axes appear white, while horizontal $c$ axes appear in full colors depending on their azimuth (see color code in the legend). (a) and (c) refer to different surfaces as shown in the cutting plan (d) and thus the grain boundary networks are not corresponding (3-D effect). (d) Cutting plan of the sample preparation.

Around $70 \%$ of analyzed $\mu$ inclusions showed a Raman spectrum of sufficiently high intensity to separate it from the overall present ice spectrum. The quality of obtained Raman signal depends on several factors. The most limiting ones are the size of the $\mu$ inclusion, the path length of the laser beam through the crystal, the quality of polished surface and the acquisition time. Due to time constraint given the large amount of measured points, integration time was in the range 5-10 s with 10 repetitions. Most of the measured inclusions in EDML-2371.4 and EDML-2371.9 - around 40 spectra could be identified as sulfate salts (see example spectrum in Fig. 2e). The NEEM samples showed a higher content of water-insoluble inclusions, such as quartz and black carbon. A detailed description of the composition statistics is still in progress and will be shown elsewhere. However, the Raman measurements show that the counted black dots are chemical impurities and thus verify microstructure mapping as a valid method to map the visible in situ impurity content.

\subsection{Concentration}

The number of counted $\mu$ inclusions per sample are shown in Table 1. Knowing the depth of field being $200 \mu \mathrm{m}$ we calculated the volume fraction of the mapped area. In this way, the average concentration of $\mu$ inclusions per $\mathrm{ml}$ of water equivalent could be estimated. Comparison with the CFA dust concentration shows a clear difference between the deep EDML ice and the shallow NEEM ice. In EDML, the number of visible $\mu$ inclusions in situ is $2-3$ times higher than the content of insoluble particles (dust) in the meltwater. In contrast the amount of $\mu$ inclusion in the NEEM samples is comparable or even less than the CFA dust concentration. 
Table 1. Black dots from optical microscopy versus dust concentration from CFA (Wegner et al., 2015). With the sample size, the focus range of $200 \mu \mathrm{m}$ and the density of the ice we estimate the concentration of $\mu$ inclusions. The density of the samples has been estimated using images of air bubble density.

\begin{tabular}{lllll}
\hline Ice core & EDML & & NEEM & \\
Sample & 2371.9 & 2371.4 & 1346.2 & 1346.5 \\
Depth $(\mathrm{m})$ & 2370.9 & 2370.4 & 739.9 & 740.2 \\
\hline Sample size $(\mathrm{mm})$ & $76 \times 17$ & $80 \times 21$ & $71 \times 21$ & $74 \times 23$ \\
Total number of $\mu$ inclusions & 2527 & 1195 & 1145 & 917 \\
Ice density $\left(\mathrm{g} \mathrm{mL}^{-1}\right)$ & 0.9167 & 0.9167 & 0.9079 & 0.9079 \\
Number of $\mu$ inclusions/mL water & 10668 & 4972 & 4197 & 3019 \\
Dust particles/mL water $(\mathrm{CFA})$ & 3575 & 2645 & 5450 & 3823 \\
\hline
\end{tabular}

\subsection{Distribution}

\subsubsection{General spatial distribution}

The distributions of $\mu$ inclusions within the four samples are highly inhomogeneous. Similarly to ice-age ice (cloudy ice), the cleaner Holocene and Eemian ice (MIS5.5) also contains horizontal layers of increased impurity concentrations (analogous to cloudy bands) instead of $\mu$ inclusions being distributed homogeneously.

In the EDML-2371.9 sample more than $50 \%$ of the counted black dots can be allocated to one of these horizons. We can distinguish a sharp double horizon at $2370.95 \mathrm{~m}$ (Fig. 3a, central part of the sample). This sharp double layer correlates with a cloudy band in the visual stratigraphy scanning image (Fig. 3b) and with dust and calcium peaks in the CFA profile. Around $9 \mathrm{~mm}$ below, there is another (disrupted) impurity layer at $2370.96 \mathrm{~m}$ and one more at the bottom part of the section around $2370.99 \mathrm{~m}$. In the sample EDML-2371.4 (Fig. 5) the layers are not as sharp as in 2371.9 but horizons of higher and lower concentrations are clearly visible. The NEEM samples (Fig. 6) also show horizontal layering, but they are not so well defined and more continuous.

While the distribution of $\mu$ inclusions on the centimeter scale occurs in horizontal or sub-horizontal layers, on the micrometer scale they are often aggregated in clusters. These groups of two or more adjacent black dots are typical for both - regions with low concentration as well as high-impurity layers.

\subsubsection{Distribution with respect to microstructure}

Grain boundary grooves from microstructure mapping of the sample surfaces are highlighted in Figs. 3, 5, 6 with blue lines of a thickness of $300 \mu \mathrm{m}$. This width was chosen to represent the possible grain boundary position error rising from the unknown inclination of the grain boundary below the sample surface. In Table 2, $\mu$ inclusions located within this blue range are considered as potentially interacting with the grain boundary. This is an upper-limit assumption, considering the fact that a real grain boundary is not thicker than only a few $\mathrm{nm}$. Table 2 shows the fraction of $\mu$ inclusions found within a range of $300 \mu \mathrm{m}$ around a grain boundary. The percentages clearly show that the vast majority of $\mu$ inclusions are located away from grain boundaries. In EDML-2371.4, $89 \%$ of $\mu$ inclusions are situated further than $150 \mu \mathrm{m}$ away from any grain boundary. In EDML-2371.9, the percentage of $93 \%$ of $\mu$ inclusions not located in the vicinity of grain boundaries is even higher. Slightly higher percentages of $\mu$ inclusions related to grain boundaries are observed in the NEEM samples: 24 and $15 \%$. The "grain boundary region" in both sample types has been kept constant for observational reasons such as same imaging resolution, similar focus depth of impurity maps and unknown grain boundary inclination. However, the NEEM samples show a significantly smaller grain size (mean radius $1.5 \mathrm{~mm}$ ) compared to the EDML samples (mean radius $2.5 \mathrm{~mm}$; Weikusat et al., 2009).

In general no correlation between $\mu$ inclusions and grain boundaries could be detected in any of the analyzed samples. Instead, the distinctive horizons 2 and 3 in EDML-2371.9 are located inside big grains, several millimeters away from the nearest grain boundaries.

In both EDML samples we observe high accumulations of secondary gas inclusions along grain boundaries, which are formed due to relaxation of the material (Weikusat et al., 2012). Their high densities allow us to partly reconstruct the 3 -D shape of the grain boundary just by means of the microbubbles (Figs. 2, 5).

The concentration of $\mu$ inclusions and clusters seems not to depend on shape, size or crystal orientation of individual grains (Fig. 3c). Black dots follow sub-horizontal layering as mentioned above rather than any microstructural feature.

\section{Discussion}

\subsection{Impurities in the form of $\mu$ inclusions}

We used a microscopic method to map visible impurities within the ice sample volume. Since $\mu$ inclusions are mapped in situ, surface contamination of the sample does not affect 
the results. The method is limited mainly by the optics of our system, in particular contrast and resolution. Objects smaller than a certain size limit would be virtually not resolved and thus a fraction of small-sized $\mu$ inclusions would be excluded from the analysis. Wegner et al. (2015) analyzed size distributions of dust particles in the EDML ice core using a laser particle detector. The average particle diameter varied between 2 and $3 \mu \mathrm{m}$ and only a small fraction of dust particles were smaller than $1 \mu \mathrm{m}$ in diameter. Thus, the majority of microparticles were indeed within the resolution range of an optical microscope and our results should be comparable to the CFA dust data. Individual $\mu$ inclusions were selected for Raman measurements. The obtained spectra confirmed that the optically detected "black dots" are chemical impurities, mainly salt and dust particles. This supports previous studies by Ohno et al. (2005, 2006) and Sakurai et al. (2011) who used Raman microscopy to analyze $\mu$ particles in ice from Dome Fuji. Detailed quantitative studies on composition and size of $\mu$ inclusions are ongoing to estimate the actual proportion of substances present as inclusions or dissolved within the ice lattice respectively.

No signal other than ice spectrum could be detected when focusing into grain interiors, grain boundaries or triple junctions. In all four samples presented in our study, impurity spectra could be detected only when focusing onto visible $\mu$ inclusions. Thus we cannot confirm observations by Fukazawa et al. (1998) and Barletta et al. (2012), who measured acidic environments in triple junctions and grain boundaries via Raman spectroscopy, nor EDX analyses by e.g., Cullen and Baker (2001) and Iliescu and Baker (2008), who also found trace elements in grain boundaries. The AWI cryo-Raman should be considered one of the most powerful Raman systems applied to ice. Still, its spatial resolution and sensitivity are limited by the applied optics and by the physics of Raman scattering. Thus, we cannot rule out segregation of trace elements to grain boundaries if their concentrations were very low.

High-resolution CFA dust concentrations measured by Wegner et al. (2015) were taken as reference for comparison with our concentrations of $\mu$ inclusions (Table 1). The ratios dust vs. $\mu$ inclusions differ significantly between the two ice cores. The deep EDML ice in solid state contains 2-3 times more $\mu$ inclusions per volume unit than dust in the meltwater (CFA; Wegner et al., 2015). In contrast, the NEEM samples contain comparable amounts of $\mu$ inclusions and dust. However, the NEEM CFA data still need to be flux-calibrated (Wegner, personal communication). Additionally, the presence of air bubbles in the shallower NEEM samples may cause an underestimation of $\mu$-inclusion concentration. As air inclusions appear dark in the impurity maps (Fig. 6), they may cover a substantial part of $\mu$ inclusions in the image. Another possible explanation is to assume that the NEEM samples contain predominantly insoluble dust particles which are detected in the CFA, whereas the EDML $\mu$ inclusions consist mainly of water-soluble substances. The preliminary analysis of the collected Raman spectra points in this direction. While the two Antarctic samples feature primarily sulfate salts (in agreement with Ohno et al., 2006), we mainly found terrestrial minerals and black carbon in the Greenland samples.

$\mu$ inclusions are distributed in horizontal bands or layers of higher concentration. The annual layer thickness at $740 \mathrm{~m}$ in the NEEM ice core was estimated as $12-16 \mathrm{~cm}$ (Rasmussen et al., 2013). Thus at most one annual layer would fit in one section and the layering of $\mu$ inclusions in NEEM-1346.2 and NEEM-1346.5 is probably attributed to seasonal variability. The annual layer thickness of the EDML samples $(2371 \mathrm{~m})$ is only $5-10 \mathrm{~mm}$ (Ruth et al., 2007) so that more than 10 annual layers should be present in each sample. However, the stratigraphy at this depth of the EDML ice core is strongly disrupted, strata are tilted by up to $30^{\circ}$ and centimeter-sized $z$ folds are present (Faria et al., 2010). The visual stratigraphy, CFA profile and $c$-axis orientations along the whole EDML bag 2371 are plotted in Fig. 4. Impurity layers are visible in the line scanner image and correlate with peaks in the dust and $\mathrm{Ca}^{2+}$ record. A sharp impurity peak is visible in the EDML-2371.9 section, which corresponds to the double horizon of $\mu$ inclusions shown in Figs. $2 b$ and 3. The DEP and CFA conductivities show significant differences, as DEP is recorded on the ice core in solid state while CFA measures the electrolytic conductivity of the meltwater. The DEP variability is independent on dust and $\mathrm{Ca}^{2+}$ concentration, while the CFA conductivity shows a sharp peak in EDML-2371.9 correlated to the dust and $\mathrm{Ca}^{2+}$ horizon. This supports our conclusion from the last paragraph stating that a large portion of the $\mu$ inclusions in the EDML samples are water-soluble salts, which will increase the CFA conductivity. Another dust peak arises in sample EDML-2371.4, but no correlated signal is found in $\mathrm{Ca}^{2+}$ nor CFA conductivity. Furthermore, it is unclear whether the $\mathrm{NH}_{4}^{+}$peak in EDML-2371.4 is correlated to the mentioned dust peak and the shift is due to inaccuracy in depth assignment or the signals are independent. Further evaluation of the Raman spectra, which will be presented elsewhere, should help to better understand the origin of the signals.

\subsection{Zener pinning}

The attractive force between a grain boundary and $\mu$ inclusions results from the reduction of grain boundary energy. Assuming a random distribution of spherical inclusions of radius $r$ (Humphreys and Hatherly, 2004), the maximal pinning pressure on a grain boundary can be derived:

$P_{Z}=2 \pi r^{2} \gamma N_{\mathrm{V}}$,

where $\gamma$ is the grain boundary energy and $N_{\mathrm{V}}$ number of $\mu$ inclusions per volume unit. If the driving force for grain boundary migration $P_{\mathrm{GBM}}<P_{Z}$, then the grain boundary stays in contact with the pinning particles and its migration rate adapts to the mobility of the particles (slow-mode pinning). In contrast, if $P_{\mathrm{GBM}}>P_{Z}$, the interaction time is short 
Table 2. Counted $\mu$ inclusions in the vicinity of grain boundaries (region of $300 \mu \mathrm{m}$ thickness along grain boundaries) obtained from stacked microstructure maps with grain boundary grooves on the surface and impurity maps focused inside the sample (ca. $300 \mu \mathrm{m}$ below the sample surface).

\begin{tabular}{lllll}
\hline Ice core & EDML & \multicolumn{3}{c}{ NEEM } \\
Sample & 2371.9 & 2371.4 & 1346.2 & 1346.5 \\
Depth $(\mathrm{m})$ & 2370.9 & 2370.4 & 739.9 & 740.2 \\
\hline Total number of $\mu$ inclusions & 2527 & 1195 & 1145 & 917 \\
$\mu$ inclusions within $300 \mu \mathrm{m}$ around a grain boundary & 183 & 127 & 278 & 164 \\
Percentage & $7 \%$ & $11 \%$ & $24 \%$ & $18 \%$ \\
\hline
\end{tabular}

and grain boundary proceeds with its motion, leaving the particles behind (fast-mode pinning).

One of the objectives of our study was to catch $\mu$ inclusions "in flagrante" - i.e., in the very act of pinning a grain boundary. However, this aim resulted to be cumbersome since grain boundaries are usually invisible inside the sample volume. In general, we can only estimate positions of grain boundaries from the surface images (microstructure maps). Sometimes, if the curvature and convexity are favorable with respect to the image plane, 3-D shapes of grain boundaries are indeed visible within the sample volume. In such cases, we could observe clathrate hydrates sticking to grain boundary interfaces, deforming their shapes due to the pinning force. However, no $\mu$ inclusions were observed to produce such kind of effects. We studied the distribution of $\mu$ inclusions in a plane of focus over the whole sample area. The density of $\mu$ inclusions is inhomogeneous but exhibits no correlation with grain boundaries. The typically clustered distribution could in principle be interpreted as caused by sudden release of $\mu$ inclusions from accelerating grain boundary. However, the clusters which are within themselves unordered also are of no significant shape, e.g., rows, planes or ellipsoids. We would expect some kind of alignment in rows or planes or at least some sort of graduation (size, type) of the clusters if they would result from release by a moving grain boundary.

The observations listed above lead us to the conclusion that only fast-mode pinning can take place in all four analyzed samples:

$P_{\mathrm{GBM}}>P_{Z}$.

This is in agreement with Alley et al. (1986b), Paterson (1991) and others, who suggest that particle concentrations in ice are in general too low to induce slow-mode pinning. However, we cannot confirm the assumption by Durand et al. (2006) that $\mu$ inclusions would accumulate in high concentrations at grain boundaries. Our results also confirm general observations by Faria et al. (2010) and Svensson et al. (2011), who concluded that impurity layering and thus climatic record would stay preserved even in the deep parts of the EDML ice core and the NGRIP ice core respectively. Svensson et al. (2011) identified annual layering of impurities down to the Eemian part of the NGRIP ice core.
Faria et al. (2010) observed no redistribution of $\mu$ inclusions due to pinning or dragging down to $2300 \mathrm{~m}$ of the EDML ice core. However, below this depth, and particularly in the deepest $200 \mathrm{~m}$, the authors found accumulations of "black dots" along grain boundaries and concluded that pinning and dragging is relevant only in the deepest part of the EDML ice core. This finding mismatched our observations in EDML-2371.4 and EDML-2371.9, where we only found secondary bubbles accumulated along grain boundaries. Since microstructure maps described by Faria et al. (2010) were made only few days or hours after drilling the ice core, we decided to record new microstructure maps of the same spots now after ca. 10 years of storage. The comparison indicates that significant changes occur during the relaxation of the material (see example in Fig. 7). The image of the freshly drilled ice shows a group of "black dots" accumulated at a grain boundary. The image of a re-measurement of the same sample shows that with time these "black dots" have grown and filled with gas and now they are forming typical relaxation air bubbles. There are two possible explanations. (1) Grain boundaries in deep EDML do collect $\mu$ inclusions by dragging but after retrieving the core they serve as seeds for the growing relaxation bubbles and get surrounded with gas. It remains unclear why $\mu$ inclusions in the interior of grains do not evolve into bubbles. (2) Another option is that the "black dots" at grain boundaries observed by Faria et al. (2010) in fact are small micro-bubbles forming due the abrupt drop of pressure after logging the ice core. Weikusat et al. (2012) analyzed compositions of secondary microbubbles using Raman spectroscopy. The authors also remark that secondary bubbles tend to form at locations of "black dots". However, to date there are no data available concerning the composition of these original "black dots" as Raman spectroscopy is currently not available on-site, viz. right after drilling.

Della Lunga et al. (2014) observed impurity concentration peaks at grain boundaries in the clean parts of the Greenland Stadial 22, NGRIP ice core, using LA-ICPMS. However, fundamental differences between the experimental techniques as well as the ice samples impede a direct comparison to our study. Dust concentrations in GS-22 determined by Vallelonga et al. (2012) vary between $2 \times 10^{5} \mathrm{~mL}^{-1}$ in 


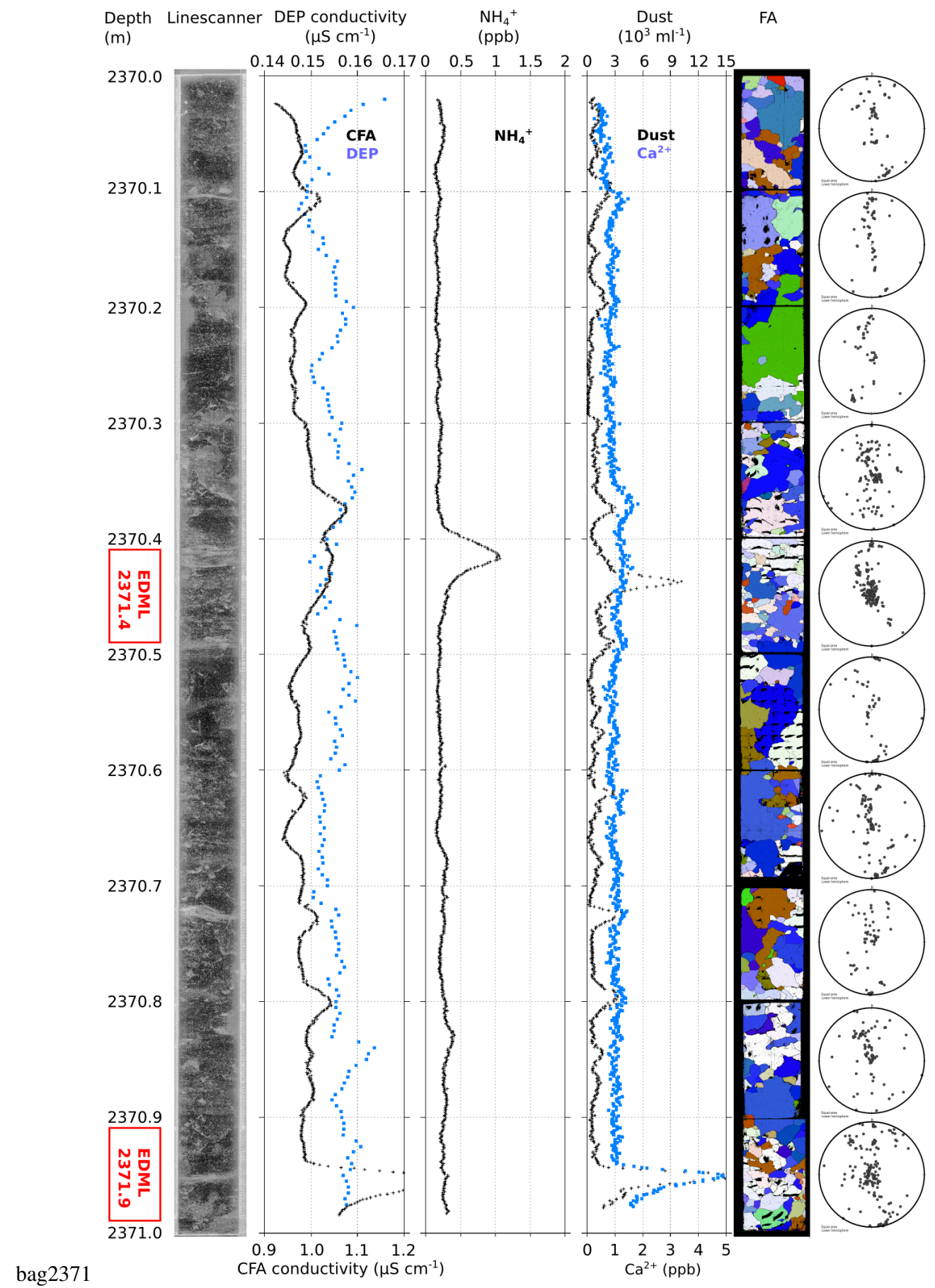

Figure 4. EDML one meter core section (2370-2371 m). From left to right: visual stratigraphy (Lambrecht et al., 2004), DEP and CFA conductivity, $\mathrm{NH}_{4}^{+}, \mathrm{Ca}^{2+}$ and dust profile (CFA; Kaufmann et al., 2010; Wegner et al., 2015), and $c$-axis orientations projected into the horizontal plane with the corresponding Schmidt diagrams.

cloudy bands and $2 \times 10^{4} \mathrm{~mL}^{-1}$ in the clean bands, which is 1 order of magnitude more than the average concentrations in our samples. Furthermore, it remains unclear what portion of the LA-ICPMS signal is due to visible $\mu$ inclusions. A comparative study applying both techniques to the same specimen could help resolve the contradiction.
The highest local $\mu$-inclusion density in our sample material was found in the double horizon of sample EDML2371.9 (Figs. 2, 3) and could be estimated as $N_{\mathrm{V}}=$ $37206 \mathrm{~cm}^{-3}$. When inserting this value in Eq. (1), assuming the mean particle radius $r=1.5 \mu \mathrm{m}$ (in agreement with Wegner et al., 2015) and using $\gamma=65 \mathrm{~mJ} \mathrm{~m}^{-2}$ for high an- 


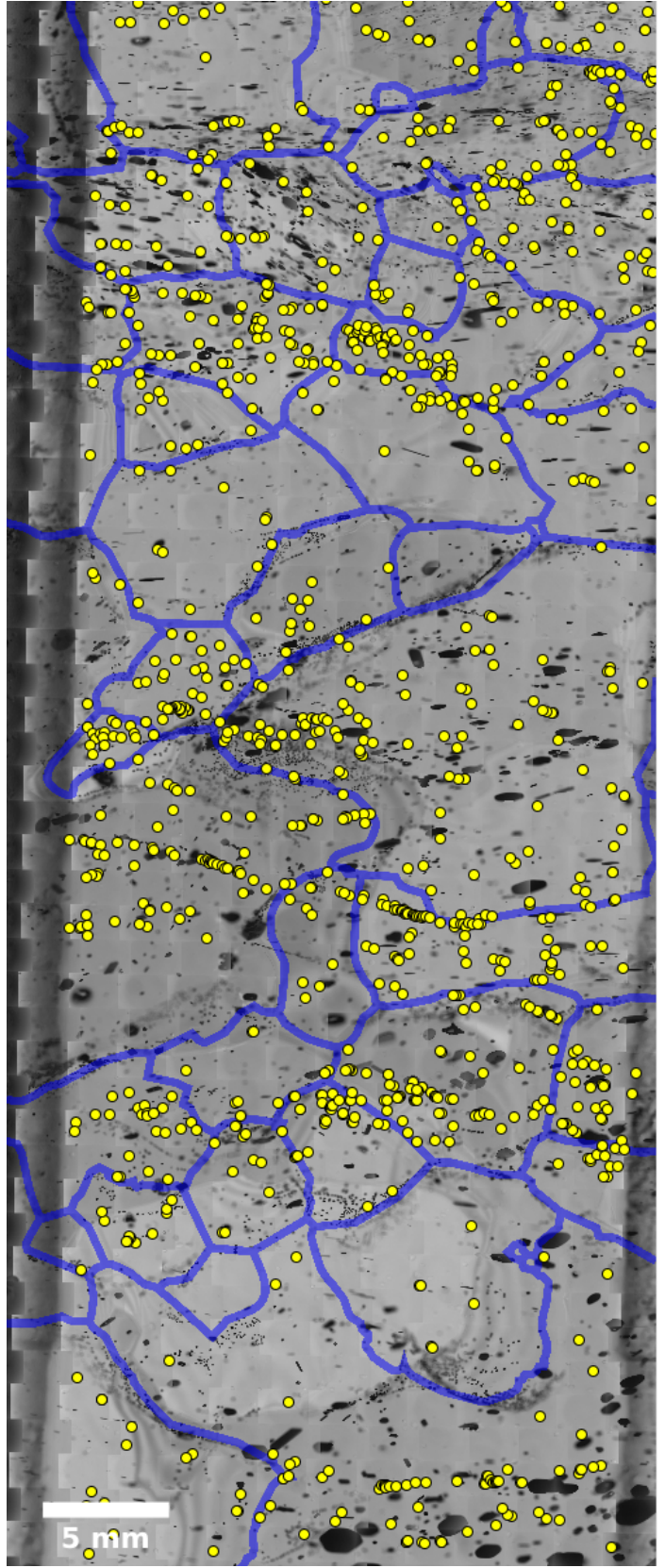

Figure 5. Microstructure and impurity map of the sample EDML2371.4. Layering of $\mu$ inclusions (yellow) is less pronounced than in EDML-2371.9. Secondary gas inclusions (small, black and roundish) tend to follow the shapes of grain boundaries. In contrary, the $\mu$ inclusions seem not to accumulate at grain boundaries.

gle boundaries (Hobbs, 1974), we obtain the maximal pinning pressure $P_{Z}=0.034 \mathrm{~N} \mathrm{~m}^{-2}$. The driving force for grain boundary migration can be written as

$P_{\mathrm{GBM}}=\Delta H-\frac{2 \gamma}{R}$,

where $\Delta H$ is the gradient in stored strain energy density across the grain boundary (i.e., strain-induced driving pres-

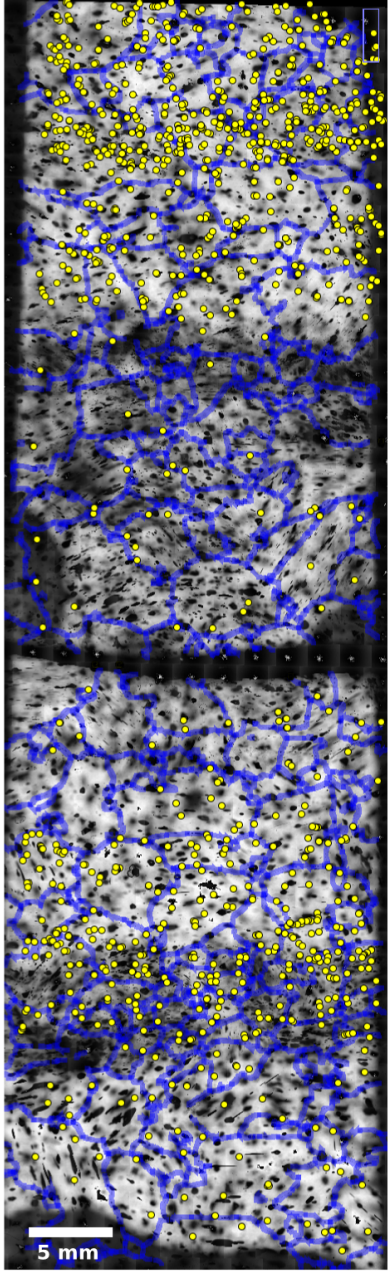

NEEM 1346.2

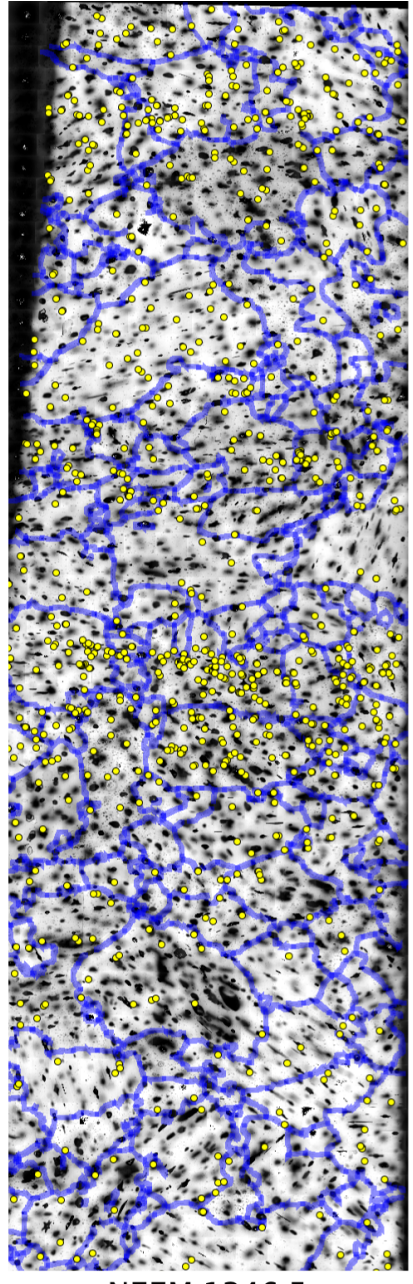

NEEM 1346.5
Figure 6. Microstructure and impurity maps of the two NEEM samples $(740 \mathrm{~m})$. Horizontal layering of $\mu$ inclusions is present in both maps. The samples contain a higher density of grain boundaries, the average grain radius is $1.5 \mathrm{~mm}$. NEEM-1346.2 is cracked in the central part. In contrast to the EDML samples, the gas inclusions (black) are homogeneously distributed, since they are primary air bubbles, albeit deformed due to relaxation.

sure) and the second term represents the curvature-driven pressure with the radius $R$ of grain boundary local curvature. Assuming no difference in stored strain energy $(\Delta H=0)$, the boundary migration will be driven only by its curvature. Inserting $P_{Z}$ and Eq. (3) into Eq. (2) we obtain $R<3.8 \mathrm{~m}$ the radius of local curvature necessary to unpin the grain boundary from its surrounding $\mu$ inclusions. Most grain boundaries along the NEEM and EDML ice cores indeed fulfill this condition (e.g., Binder et al., 2013).

In a second marginal case, let us consider a planar grain boundary $(R \rightarrow \infty)$ whose migration is only driven by the difference in stored strain energy as function of the local dislocation density $\Delta \rho_{\text {dis }}$. Following Humphreys and Hatherly (2004) and Llorens Verde et al. (2016), $\Delta H$ can be approxi- 


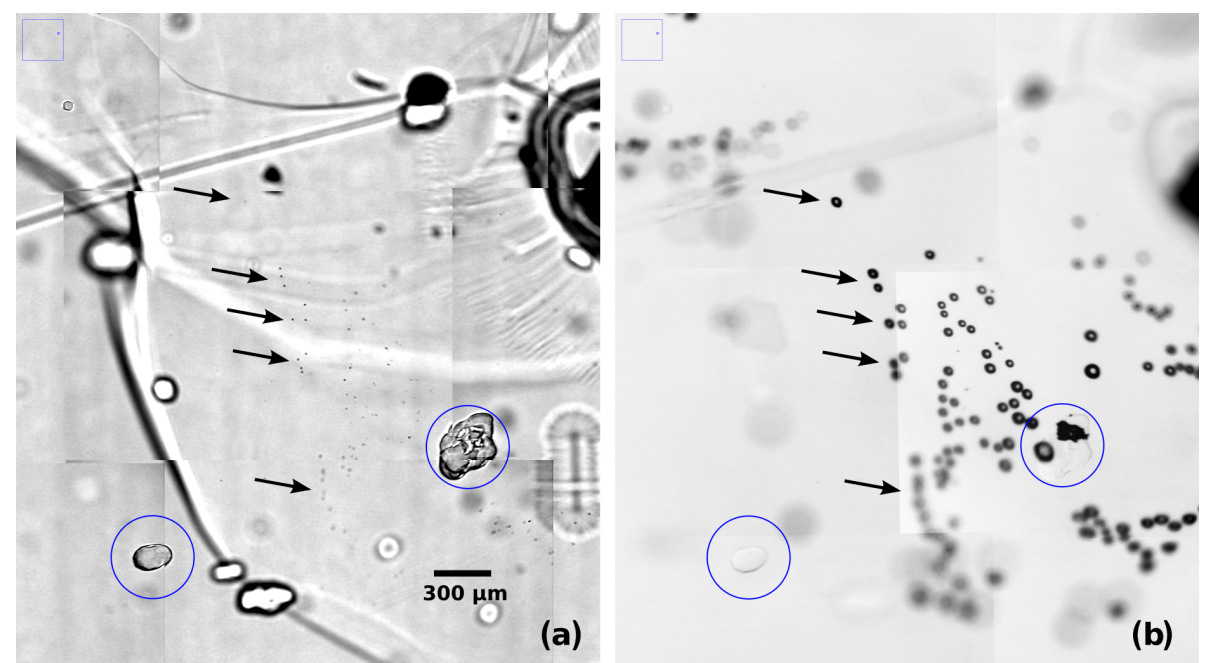

Figure 7. Two images of the same spot in EDML-2376.0. Two clathrate hydrates are highlighted (blue circles) in both images for comparison. (a) Photomicrograph taken at the site immediately after drilling the ice core in 2006. An accumulation of "black dots" within the grain boundary plane can be recognized. These "black dots" are slightly larger than the $\mu$ inclusions counted in our impurity maps. (b) The same spot after ca. 10 years of relaxation. Almost all "black dots" at the grain boundary evolved into secondary gas inclusions.

mated as

$\Delta H=\Delta \rho_{\text {dis }} \frac{1}{2} G b^{2}$,

where $G b^{2} / 2$ is the energy per unit length of a single dislocation line consisting of the shear modulus $G$ and the magnitude of the Burgers vector $b$. Considering only the basal slip system the mean dislocation energy can be estimated as $G b^{2} / 2=3.6 \times 10^{-10} \mathrm{~J} \mathrm{~m}^{-1}$. Inserting this in Eq. (4) and combining Eqs. (4), (3) and (2) we obtain an estimation for the minimal difference in dislocation density required for unpinning: $\Delta \rho_{\text {dis }}>10^{8} \mathrm{~m}^{-2}$. This value is $2-3$ orders of magnitude smaller than absolute dislocation densities modeled by Montagnat and Duval (2000) and Montagnat et al. (2003) and also smaller than a minimum dislocation density access calculated from grain boundary curvatures by Hamann et al. (2007, Fig. 11b).

In the above considerations we made a variety of assumptions and the derived values are only for approximation. Furthermore, in the case of a real grain boundary $\Delta H$ acts against the curvature-driven force as described in Eq. (3) and thus the final motion and shape are determined by the ratio of these forces. However, the exercise demonstrated that applying Zener's theory to our particular $\mu$-inclusion concentration the pinning effect is comparatively small and will hardly affect grain boundary migration. This is indeed in agreement with what we observe.

\subsection{Grain size controlling mechanisms}

It is difficult to make general conclusions based on the analysis of four discrete samples. Our study indicates that pinning on $\mu$ inclusion occurs in fast mode in a large part of the ice sheets, as already stated by Alley et al. (1986b), and will not significantly affect grain boundary migration. At the same time, with our Raman microscope we find no other form of, for example, dissolved impurities segregated to grain boundaries. However, negative correlations between average grain size and impurity content were found in virtually all ice cores (e.g., Gow and Williamson, 1976; Gow et al., 1997; Lipenkov et al., 1989; Azuma et al., 1999, 2000; Thorsteinsson et al., 1995; Durand et al., 2009). High-impurity ice exhibits generally smaller grains than low-impurity ice at the same depth. This negative correlation can be found at all scales: in seasonal variabilities (cloudy bands, $\mathrm{cm}$ ), during rapid climatic fluctuations such as Dansgaard-Oeschger events (tens of meters) or comparing glacial and interglacial periods (hundreds of meters).

Grain size has an impact on a variety of ice physical properties (Goldsby, 2006; Cuffey, 2006); vice versa it is controlled by thermodynamic conditions and processes within the ice sheet. Without deformation and under purely static conditions, mean grain area increases linearly with time. This NGG is driven by the reduction of grain boundary surface energy (Alley et al., 1986a) due to the optimization of volume versus interfaces. This model is especially relevant for very small grain sizes well below the equilibrium or steady-state grain size (see, e.g., Jacka and Jun, 1994; Faria et al., 2014b), such as smallest grain sizes in the uppermost part of the ice sheet (Gow, 1969), but may also apply to some areas where topographic depressions in the bedrock below ice sheets inhibit deformation and NGG can produce extraordinary large grain sizes (stagnant ice; Budd and Jacka, 1989). If deformation introduces additional energy into the system, dynamic recrystallization processes are activated, driven by the en- 
ergy reduction. Rotation recrystallization (RRX) splits grains into subgrains and thus has a grain-size-reducing effect (Durand et al., 2008; Alley et al., 1995; Wang et al., 2003). During RRX recovery orders dislocations of a deformed grain into subgrain boundaries, which are lower energy states of dislocation assemblages (Hirth and Lothe, 1982; Hondoh, 2010). Subgrain boundaries can develop into grain boundaries by further rotation. In contrast, strain-induced boundary migration (SIBM) occurs when grain boundaries propagate into regions of high dislocation densities. The effectiveness of SIBM increases with the heterogenous distribution of dislocations (Weikusat et al., 2009) in polycrystalline ice, which is a direct consequence of the high mechanical anisotropy of the ice crystal. SIBM leads to huge grain sizes in the deep ice (De La Chapelle et al., 1998) but can also lead to grain size reduction, e.g., by nucleation of new grains (SIBM-N; Faria et al., 2014b) or by dissection of highly irregular grains. Recent microstructural studies (e.g., Durand et al., 2008; Faria et al., 2014a) show that all recrystallization mechanisms (NGG, RRX and SIBM) concur all over the depth range of an ice sheet rather than being dominantly active in separate depth zones. The grain size is then a product of the interplay between these processes (dynamic grain growth; Faria et al., 2014b).

It is widely accepted that the grain size is modulated by some impurity effect. The two most manifest candidates for such an effect are (1) reduction of grain boundary mobility via dissolved impurities being dragged along by migrating grain boundaries (Alley et al., 1986b; Alley and Woods, 1996; Urai et al., 1986; Drury and Urai, 1990; Paterson, 1991); (2) Zener pinning (Fisher and Koerner, 1986; Durand et al., 2006), that is, interaction between $\mu$ inclusions and grain boundaries as discussed in Sect. 4.2. However, experimental evidences for both models are controversial in ice, as demonstrated by our study. Furthermore, both interpretations are based on the assumption that it is solely NGG, which suffers under the effect of impurities leading to smaller grain sizes. However, grain size is a product of all recrystallization processes together, as discussed previously. Therefore we hypothesize that an indirect impurity effect, for instance enhanced deformation and/or effect on dynamic recrystallization triggered by high impurity content, could be an alternative candidate responsible for the changes in grain size. Impurities could have a significant influence on strain distribution within grains as well as dislocation mobilities and densities, e.g., via dislocation multiplication. The microstructure effects of increasing dynamic recrystallization versus viscoplastic deformation have recently been tested by a microstructural evolution model (Llorens, 2016a, b). In these model runs the impact is significant on, e.g., the grain shape evolution because deformation tends to flatten grains while recrystallization tends to make them equidimensional. First evidences of changes in the deformation-recrystallization interplay have been observed by means of grain shape analyses
(Weikusat et al., 2016; Binder et al., 2013). However, to test these hypotheses is far beyond the scope of this study.

\section{Summary}

We present high-resolution large-scale maps $\left(3 \mu \mathrm{mpix}^{-1}\right.$, $8 \times 2 \mathrm{~cm}^{2}$ ) of $\mu$ inclusions within four samples from polar ice cores: two from the EDML $(2371 \mathrm{~m})$ and two from the NEEM ice core $(740 \mathrm{~m})$. For the first time, in situ distributions of a representative number (more than 5000) of $\mu$ inclusions have been studied. A confocal Raman microscope has been used to prove the impurity origin of the inclusions. Discrete $\mu$ inclusions are the only impurity form detected in this study; i.e., we measured no signal attributed to dissolved impurities neither in grain interiors nor in grain boundaries. The comparison with grain boundary network shows no correlation between $\mu$ inclusions and grain boundaries. Therefore we observed evidence for neither redistribution of impurities by dragging nor slow-mode grain boundary pinning as defined by Alley et al. (1986b). The link between grain size and impurities may not be (only) due to hindered normal grain growth in impurity-rich ice. Deformation and dynamic recrystallization enhanced by impurities possibly also have a grain-size-reducing effect.

Data availability. The four impurity maps in original resolution and positions of individual micro-inclusions are available upon request and will be published in PANGAEA in the future. Thicksection images along the whole EDML ice core are available at doi:10.1594/PANGAEA.663141.

Author contributions. J. Eichler, I. Kleitz and W. Shigeyama performed the measurements, processing and interpretation. M. BayerGiraldi, D. Jansen, S. Kipfstuhl, C. Weikusat and I. Weikusat supported the processing and interpretation of data by providing specialists knowledge as well as the general glaciological framework. I. Weikusat provided the initial concept. Under the lead of J. Eichler all authors contributed to writing of the manuscript.

Competing interests. The authors declare that they have no conflict of interest.

Acknowledgements. This research was funded by HGF grant VH-NG-802 to J. Eichler and I. Weikusat, SPP 1158 DFG grant WE4711/2 to C. Weikusat, as well as DFG grant SPP 1158 BA 3694/2-1 and JSPS fellowship ID PE16746 to M. Bayer-Giraldi. The Microdynamics of Ice (MicroDICE) research network, funded by the European Science Foundation, is acknowledged for funding research visits of J. Eichler and I. Kleitz (short visit grant). We thank Anna Wegner, Melanie Behrens and Maria Hörhold for discussions on solubility of impurities and CFA-related issues. The visual stratigraphy line scan image has been made available at 
www.pangaea.de. We thank the logistics and drilling team of the Kohnen and NEEM stations. NEEM is directed and organized by the Center of Ice and Climate at the Niels Bohr Institute and US NSF, Office of Polar Programs. It is supported by funding agencies and institutions in Belgium (FNRS-CFB and FWO), Canada (NRCan/GSC), China (CAS), Denmark (FIST), France (IPEV, CNRS/INSU, CEA and ANR), Germany (AWI), Iceland (RannIs), Japan (NIPR), Korea (KOPRI), the Netherlands (NWO/ALW), Sweden (VR), Switzerland (SNF), UK (NERC) and the USA (US NSF, Office of Polar Programs). This work is a contribution to the European Project for Ice Coring in Antarctica (EPICA), a joint European Science Foundation/ European Commission (EC) scientific programme, funded by the EC and by national contributions from Belgium, Denmark, France, Germany, Italy, the Netherlands, Norway, Sweden, Switzerland and the UK.

The article processing charges for this open-access publication were covered by a Research

Centre of the Helmholtz Association.

Edited by: F. Dominé

Reviewed by: J. L. Urai and A. Svensson

\section{References}

Alley, R., Gow, A., and Meese, D.: Mapping c-axis fabrics to study physical processes in ice, J. Glaciol., 41, 197-203, 1995.

Alley, R. B. and Woods, G. A.: Impurity influence on normal grain growth in the GISP2 ice core, Greenland, J. Glaciol., 42, 255260, 1996.

Alley, R. B., Perepezko, J. H., and Bentley, C. R.: Grain Growth in Polar Ice: I. Theory, J. Glaciol., 32, 415-424, 1986a.

Alley, R. B., Perepezko, J. H., and Bentley, C. R.: Grain Growth in Polar Ice: II. Application, J. Glaciol., 32, 425-433, 1986 b.

Ashby, M.: Boundary defects and the mechanism of particle movement through crystals, Scripta Metallurgica, 3, 843-848, doi:10.1016/0036-9748(69)90192-6, 1969.

Azuma, N., Wang, Y., Mori, K., Narita, H., Hondoh, T., Shoji, H., and Watanabe, O.: Textures and fabrics in Dome F (Antarctica) ice core, Ann. Glaciol., 29, 163-168, doi:10.3189/172756499781821148, 1999.

Azuma, N., Wang, Y., Yoshida, Y., Narita, H., Hondoh, T., Shoji, H., and Watanabe, O.: Crystallographic analysis of the Dome Fuji ice core, in: Physics of Ice Core Records, edited by: Hondoh, T., Hokkaido University Press, Sapporo, 45-61, 2000.

Baker, I., Cullen, D., and Iliescu, D.: The microstructural location of impurities in ice, Can. J. Phys., 81, 1-9, doi:10.1139/p03-030, 2003.

Barletta, R. E., Priscu, J. C., Mader, H. M., Jones, W. L., and Roe, C. H.: Chemical analysis of ice vein microenvironments: II. Analysis of glacial samples from Greenland and Antarctica, J. Glaciol., 58, 1109-1118, doi:10.3189/2012JoG12J112, 2012.

Barnes, P. R. F.: Comment on "Grain boundary ridge on sintered bonds between ice crystals" [J. Appl. Phys. 90, 5782 (2001)], J. Appl. Phys., 93, 783-785, doi:10.1063/1.1521800, 2003.

Barnes, P. R. F., Mulvaney, R., Robinson, K., and Wolff, E. W.: Observations of polar ice from the Holocene and the glacial period using the scanning electron microscope, Ann. Glaciol., 35, 559566, doi:10.3189/172756402781816735, 2002.

Binder, T., Garbe, C., Wagenbach, D., Freitag, J., and Kipfstuhl, S.: Extraction and parameterization of grain boundary networks, using a dedicated method of automatic image analysis, J. Microscopy, 250, 130-141, doi:10.1111/jmi.12029, 2013.

Budd, W. F. and Jacka, T. H.: A review of ice rheology for ice sheet modelling, Cold Reg. Sci. Technol., 16, 107-144, 1989.

Cuffey, K. M.: Glacier Science and Environmental Change, Knight, chap. Manifestation of ice microphysical processes at the scale of the whole ice sheet, Blackwell Publishing, 290-300, 2006.

Cuffey, K. M., Thorsteinsson, T., and Waddington, E. D.: A renewed argument for crystal size control of ice sheet strain rates, J. Geophys. Res., 105, 27889-27894, 2000.

Cullen, D. and Baker, I.: Observation of Impurities in Ice, Microsc. Res. Techniq., 55, 198-207, 2001.

Dahl-Jensen, D., Thorsteinsson, T., Alley, R., and Shoji, H.: Flow properties of the ice from the Greenland Ice Core Project ice core: The reason for folds?, J. Geophys. Res.-Oceans, 102, 26831-26840, doi:10.1029/97JC01266, 1997.

Dansgaard, W., Clausen, H. B., Gundestrup, N., Hammer, C. U., Johnsen, S. F., Kristinsdottir, P. M., and Reeh, N.: A New Greenland Deep Ice Core, Science, 218, 1273-1277, doi:10.1126/science.218.4579.1273, 1982.

De La Chapelle, S., Castelnau, O., Lipenkov, V., and Duval, P.: Dynamic recrystallization and texture development in ice as revealed by the study of deep ice cores in Antarctica and Greenland, J. Geophys. Res., 103, 5091-5106, 1998.

Della Lunga, D., Müller, W., Rasmussen, S., and Svensson, A.: Location of cation impurities in NGRIP deep ice revealed by cryo-cell UV-laser-ablation ICPMS, J. Glaciol., 60, 970-988, doi:10.3189/2014JoG13J199, 2014.

Drury, M. R. and Urai, J. L.: Deformation-related recrystallization processes, Tectonophysics, 172, 235-253, 1990.

Durand, G., Gagliardini, O., Thorsteinsson, T., Svensson, A., Kipfstuhl, S., and Dahl-Jensen, D.: Ice microstructure and fabric: an up-to-date approach for measuring textures, J. Glaciol., 52, 619630, doi:10.3189/172756506781828377, 2006.

Durand, G., Persson, A., Samyn, D., and Svensson, A.: Relation between neighbouring grains in the upper part of the NorthGRIP ice core - Implications for rotation recrystallization, Earth Planet. Sci. Lett., 265, 666-671, 2008.

Durand, G., Svensson, A., Kipfstuhl, S., Persson, A., Gagliardini, O., Gillet, F., Sjolte, J., Montagnat, M., and Dahl-Jensen, D.: Evolution of the texture along the EPICA dome $\mathrm{C}$ ice core, Institute of Low Temperature Science, Hokkaido University, Sapporo Japan, Nepal, vol. 68, 91-106, 2009.

EPICA community members: Eight glacial cycles from an Antarctic ice core, Nature, 429, 623-628, 2004.

EPICA community members: One-to-one coupling of glacial climate variability in Greenland and Antarctica, Nature, 444, 195198, doi:10.1038/nature05301, 2006.

Faria, S. H., Freitag, J., and Kipfstuhl, S.: Polar ice structure and the integrity of ice-core paleoclimate records, Quaternary Sci. Rev., 29, 338-351, 2010.

Faria, S. H., Weikusat, I., and Azuma, N.: The microstructure of polar ice. Part I: Highlights from ice core research, J. Struct. Geol., 61, 2-20, doi:10.1016/j.jsg.2013.09.010, 2014a. 
Faria, S. H., Weikusat, I., and Azuma, N.: The microstructure of polar ice. Part II: State of the art, J. Struct. Geol., 61, 21-49, doi:10.1016/j.jsg.2013.11.003, 2014b.

Fisher, D. and Koerner, R.: On the Special Rheological Properties of Ancient Microparticle-Laden Northern Hemisphere Ice as Derived from Bore-Hole and Core Measurements, J. Glaciol., 32, 501-510, doi:10.1017/S0022143000012211, 1986.

Fukazawa, H., Sugiyama, K., Mae, S., Narita, H., and Hondoh, T.: Acid ions at triple junction of Antarctic ice observed by Raman scattering, Geophys. Res. Lett., 25, 2845-2848, doi:10.1029/98GL02178, 1998.

Glen, J.: The effect of hydrogen disorder on dislocation movement and plastic deformation of ice, Physi. Kondens. Mater., 7, 43-51, doi:10.1007/BF02422799, 1968.

Goldsby, D. L.: Glacier Science and Environmental Change, Knight, chap. Superplastic flow of ice relevant to glacier and icesheet mechanics, Blackwell Publishing, 308-314, 2006.

Gow, A. J.: On the rates of growth of grains and crystals in south polar firn, J. Glaciol., 8, 241-252, 1969.

Gow, A. J. and Meese, D. A.: The distribution and timing of tephra deposition at Siple Dome, Antarctica: possible climatic and rheologic implications, J. Glaciol., 53, 585-596, doi:10.3189/002214307784409270, 2007.

Gow, A. J. and Williamson, T.: Rheological implications of the internal structure and crystal fabrics of the West Antarctic ice sheet as revealed by deep core drilling at Byrd Station, CRREL Rep., 76, 1665-1677, 1976.

Gow, A. J., Meese, D. A., Alley, R. B., Fitzpatrick, J. J., Anandakrishnan, S., Woods, G. A., and Elder, B. C.: Physical and structural properties of the Greenland Ice Sheet Project 2 ice core: A review, J. Geophys. Res.-Oceans, 102, 26559-26575, doi:10.1029/97JC00165, 1997.

GRIP Project Members: Climate instability during the last interglacial period recorded in the GRIP ice core, Nature, 364, 203 207, 1993.

Hamann, I., Weikusat, C., Azuma, N., and Kipfstuhl, S.: Evolution of ice crystal microstructures during creep experiments, J. Glaciol., 53, 479-489, 2007.

Hirth, J. P. and Lothe, J.: Theory of Dislocations, Krieger Publishing Company, Malabar, Florida, 2nd Edn., 1982.

Hobbs, P. V.: Ice Physics, Oxford University Press, 1974.

Hondoh, T.: An Overview of Microphysical Processes in Ice Sheets: Toward Nanoglaciology, in: Physics of Ice Core Records II, edited by: Hondoh, T., vol. 68 of Supplement Issue of Low Temperature Science, 2010.

Humphreys, F. J. and Hatherly, M.: Recrystallization and Related Annealing Phenomena, Elsevier, 2004.

Iliescu, D. and Baker, I.: Effects of impurities and their redistribution during recrystallization of ice crystals, J. Glaciol., 54, 362370,2008

Jacka, T. H. and Jun, L.: The steady-state crystal size of deforming ice, Ann. Glaciol., 20, 13-18, 1994.

Jones, S.: Softening of ice crystals by dissolved fluoride ions, Phys. Lett. A, 25, 366-367, doi:10.1016/0375-9601(67)90702-5, 1967.

Jones, S. J. and Glen, J. W.: The effect of dissolved impurities on the mechanical properties of ice crystals, Philos. Mag., 19, 1324, doi:10.1080/14786436908217758, 1969.

Kaufmann, P., Fundel, F., Fischer, H., Bigler, M., Ruth, U., Udisti, R., Hansson, M., de Angelis, M., Barbante, C., Wolff, E. W.,
Hutterli, M., and Wagenbach, D.: Ammonium and non-sea-salt sulfate in the EPICA ice cores as indicator of biological activity in the Southern Ocean, Quaternary Sci. Rev., 29, 313-323, doi:10.1016/j.quascirev.2009.11.009, 2010.

Kaufmann, P. R., Federer, U., Hutterli, M. A., Bigler, M., Schüpbach, S., Ruth, U., Schmitt, J., and Stocker, T. F.: An Improved Continuous Flow Analysis System for High-Resolution Field Measurements on Ice Cores, Environ. Sci. Technol., 42, 80448050, doi:10.1021/es8007722, 2008.

Kipfstuhl, S., Hamann, I., Lambrecht, A., Freitag, J., Faria, S., Grigoriev, D., and Azuma, N.: Microstructure mapping: a new method for imaging deformation induced microstructural features of ice on the grain scale, J. Glaciol., 52, 398-406, 2006.

Kuramoto, T., Goto-Azuma, K., Hirabayashi, M., Miyake, T., Motoyama, H., Dahl-Jensen, D., and Steffensen, J. P.: Seasonal variations of snow chemistry at NEEM, Greenland, Ann. Glaciol., 52, 193-200, doi:10.3189/172756411797252365, 2011.

Lambrecht, A., Kipfstuhl, J., Wilhelms, F., and Miller, H.: Visual stratigraphy of the EDML ice core with a linescanner, http://dx.doi.org/hdl:10013/epic.32365.d001, http://doi. pangaea.de/10.1594/PANGAEA.208005, unpublished dataset No.208005, 2004.

Legrand, M. and Mayewski, P.: Glaciochemistry of polar ice cores: A review, Rev. Geophys., 35, 219-243, doi:10.1029/96RG03527, 1997.

Lipenkov, V. Y., Barkov, N. I., Duval, P., and Pimienta, P.: Crystalline texture of the $2083 \mathrm{~m}$ ice core at vostok station, Antarctica, J. Glaciol., 35, 392-398, 1989.

Llorens Verde, M. G., Griera, A., Bons, P. D., Roessiger, J., Lebensohn, R., Evans, L., and Weikusat, I.: Dynamic recrystallisation of ice aggregates during co-axial viscoplastic deformation: a numerical approach, J. Glaciol., 62, 359-377, doi:10.1017/jog.2016.28, 2016.

Montagnat, M. and Duval, P.: Rate controlling processes in the creep of polar ice, influence of grain boundary migration associated with recrystallization, Earth Planet. Sci. Lett., 183, 179-186, doi:10.1016/S0012-821X(00)00262-4, 2000.

Montagnat, M., Duval, P., Bastie, P., Hamelin, B., and Lipenkov, V. Y.: Lattice distortion in ice crystals from the Vostok core (Antarctica) revealed by hard X-ray diffraction; implication in the deformation of ice at low stresses, Earth Planet. Sci. Lett., 214, 369-378, doi:10.1016/S0012-821X(03)00364-9, 2003.

Mulvaney, R., Wolff, E., and Oates, K.: Sulphuric acid at grain boundaries in Antarctic ice, Nature, 331, p. 247, doi:10.1038/331247a0, 1988.

Ohno, H., Igarashi, M., and Hondoh, T.: Salt inclusions in polar ice core: Location and chemical form of water-soluble impurities, Earth Planet. Sci. Lett., 232, 171-178, 2005.

Ohno, H., Igarashi, M., and Hondoh, T.: Characteristics of salt inclusions in polar ice from Dome Fuji, East Antarctica, Geophys. Res. Lett., 33, doi:10.1029/2006GL025774, 2006.

Paterson, W. S. B.: Why ice-age ice is sometimes "soft", Cold Reg. Sci. Technol., 20, 75-98, 1991.

Petrenko, V. F. and Whitworth, R. W.: Physics of ice, Oxford University Press, iSBN 0-19-851894-3, 1999.

Rasmussen, S. O., Abbott, P. M., Blunier, T., Bourne, A. J., Brook, E., Buchardt, S. L., Buizert, C., Chappellaz, J., Clausen, H. B., Cook, E., Dahl-Jensen, D., Davies, S. M., Guillevic, M., Kipfstuhl, S., Laepple, T., Seierstad, I. K., Severinghaus, J. P., Stef- 
fensen, J. P., Stowasser, C., Svensson, A., Vallelonga, P., Vinther, B. M., Wilhelms, F., and Winstrup, M.: A first chronology for the North Greenland Eemian Ice Drilling (NEEM) ice core, Clim. Past, 9, 2713-2730, doi:10.5194/cp-9-2713-2013, 2013.

Ruth, U., Barnola, J.-M., Beer, J., Bigler, M., Blunier, T., Castellano, E., Fischer, H., Fundel, F., Huybrechts, P., Kaufmann, P., Kipfstuhl, S., Lambrecht, A., Morganti, A., Oerter, H., Parrenin, F., Rybak, O., Severi, M., Udisti, R., Wilhelms, F., and Wolff, E.: "EDML1": a chronology for the EPICA deep ice core from Dronning Maud Land, Antarctica, over the last 150000 years, Clim. Past, 3, 475-484, doi:10.5194/cp-3-475-2007, 2007.

Sakurai, T., Ohno, H., Horikawa, S., Iizuka, Y., Uchida, T., Hirakawa, K., and Hondoh, T.: The chemical forms of water-soluble microparticles preserved in the Antarctic ice sheet during Termination I, J. Glaciol., 57, 1027-1032, doi:10.3189/002214311798843403, 2011.

Sigl, M., Winstrup, M., McConnell, J. R., Welten, K. C., Plunkett, G., Ludlow, F., Buntgen, U., Caffee, M., Chellman, N., Dahl-Jensen, D., Fischer, H., Kipfstuhl, S., Kostick, C., Maselli, O. J., Mekhaldi, F., Mulvaney, R., Muscheler, R., Pasteris, D. R., Pilcher, J. R., Salzer, M., Schupbach, S., Steffensen, J. P., Vinther, B. M., and Woodruff, T. E.: Timing and climate forcing of volcanic eruptions for the past 2,500 years, Nature, 523, 543-549, doi:10.1038/nature14565, 2015.

Smith, C. S.: Grains, Phases, and Interfaces: An Interpretation of Microstructure, AIME Trans., 175, 15-51, 1948.

Stillman, D. E., MacGregor, J. A., and Grimm, R. E.: The role of acids in electrical conduction through ice, J. Geophys. Res.Earth, 118, 1-16, doi:10.1029/2012JF002603, 2013.

Svensson, A., Nielsen, S. W., Kipfstuhl, S., Johnsen, S. J., Steffensen, J. P., Bigler, M., Ruth, U., and Röthlisberger, R.: Visual stratigraphy of North Greenland Ice Core Project (NorthGRIP) ice core during the last glacial period, J. Geophys. Res., D110, D2, doi:10.1029/2004JD005134, 2005.

Svensson, A., Bigler, M., Kettner, E., Dahl-Jensen, D., Johnsen, S., Kipfstuhl, S., Nielsen, M., and Steffensen, J. P.: Annual layering in the NGRIP ice core during the Eemian, Clim. Past, 7, 14271437, doi:10.5194/cp-7-1427-2011, 2011.

Taylor, K. C., Hammer, C. U., Alley, R. B., Clausen, H. B., DahlJensen, D., Gow, A. J., Gundestrup, N. S., Kipfstuhl, J. andMoore, J. C., and Waddington, E. D.: Electrical conductivity measurements from the GISP2 and GRIP Greenland ice cores, Nature, 366, 549-552, 1993.

Thorsteinsson, T., Kipfstuhl, J., Eicken, H., Johnsen, S. J., and Fuhrer, K.: Crystal size variations in Eemian-age ice from the GRIP ice core, Central Greenland, Earth Planet. Sci. Lett., 131, 381-394, 1995.
Urai, J., Means, W., and Lister, G.: Dynamic recrystallization of minerals, Mineral and Rock Deformation: Laboratory Studies: The Paterson Volume, 161-199, 1986.

Vallelonga, P., Bertagna, G., Blunier, T., Kjær, H. A., Popp, T. J., Rasmussen, S. O., Steffensen, J. P., Stowasser, C., Svensson, A. S., Warming, E., Winstrup, M., Bigler, M., and Kipfstuhl, S.: Duration of Greenland Stadial 22 and ice-gas $\Delta$ age from counting of annual layers in Greenland NGRIP ice core, Clim. Past, 8, 1839-1847, doi:10.5194/cp-8-1839-2012, 2012.

Wang, Y., Kipfstuhl, S., Azuma, N., Thorsteinsson, T., and Miller, H.: Ice-fabrics study in the upper $1500 \mathrm{~m}$ of Dome C (East Antarctica) deep ice core, Ann. Glaciol., 37, 97-104, 2003.

Wegner, A., Fischer, H., Delmonte, B., Petit, J. R., Erhardt, T., Ruth, U., Svensson, A., Vinther, B. M., and Miller, H.: The role of seasonality of mineral dust concentration and size on glacial/interglacial dust changes in the EPICA Dronning Maud Land ice core, J. Geophys. Res.-Atmos., 120, 9916-9931, doi:10.1002/2015JD023608, 2015.

Weikusat, C., Freitag, J., and Kipfstuhl, S.: Raman spectroscopy of gaseous inclusions in EDML ice core: First results - microbubbles, J. Glaciol., 58, 761-766, 2012.

Weikusat, C., Kipfstuhl, S., and Weikusat, I.: Raman tomography of natural air hydrates, J. Glaciol., 61, 923-930, doi:10.3189/2015JoG15J009, 2015.

Weikusat, I., Kipfstuhl, S., Faria, S. H., Azuma, N., and Miyamoto, A.: Subgrain boundaries and related microstructural features in EPICA-Dronning Maud Land (EDML) deep ice core, J. Glaciol., 55, 461-472, doi:10.3189/002214309788816614, 2009.

Weikusat, I., Jansen, D., Binder, T., Eichler, J., Faria, S. H., Wilhelms, F., Kipfstuhl, S., Sheldon, S., Miller, H., DahlJensen, D., and Kleiner, T.: Physical analysis of an Antarctic ice core-towards an integration of micro- and macrodynamics of polar ice, Philos. T. R. Soc. Lond. A, 375, 2086, doi:10.1098/rsta.2015.0347, 2016.

Wilhelms, F., Kipfstuhl, J., Miller, H., Heinloth, K., and Firestone, J.: Precise dielectric profiling of ice cores: A new device with improved guarding and its theory, J. Glaciol., 44, 171-174, 1998.

Wolff, E. W. and Paren, J. G.: A two-phase model of electrical conduction in polar ice sheets, J. Geophys. Res.-Sol. Ea., 89, 9433 9438, doi:10.1029/JB089iB11p09433, 1984.

Wolff, E. W., Miners, W. D., Moore, J. C., and Paren, J. G.: Factors Controlling the Electrical Conductivity of Ice from the Polar Regions - A Summary, J. Phys. Chem. B, 101, 6090-6094, doi:10.1021/jp9631543, 1997. 